\title{
PERSONAL BACKGROUND
}

1. How far do you travel from home to get to appointments here at Vanderbilt? minutes/ hours of driving

2. Guardian's (your) year of Birth:

3. Guardian's (your) Sex:

a Female

a Male

4. What is your race?

a White

․ Black or African-American

a Asian

a Pacific Islander

- American Indian or Alaska Native

ather:

5. Guardian's (your) highest level of education completed:

a Less than high school

- High school or GED

- 2 year college

- 4 year college/university

- Graduate school

6. Which one of the following categories best describes your yearly household income from all sources?

a Less than $\$ 40,000$

a $\$ 40,000$ to $\$ 59,999$

a $\$ 60,000$ to $\$ 79,999$

a $\$ 80,000$ to $\$ 99,999$

- $\$ 100,000$ and above

口 I do not know

7. What is your child's current insurance coverage?

a TennCare only

- Medicaid only

a Private insurance only

a TennCare + Medicaid

- TennCare + private insurance

- Medicaid + private insurance

a TennCare + Medicaid + private insurance 
FAMILY HISTORY OF TYPE 1 DIABETES:

1. How many children do you have? (They can be of any age. Please include children by birth, by marriage, and by adoption) (number of children)

2. For your child who has had Type 1 diabetes the longest, in what year was he/she first diagnosed? (YYYY)

3. Please rank how much you agree with this statement: "I am worried my child will develop complications from diabetes":

$\begin{array}{lllll}1 & 2 & 3 & 4 & 5\end{array}$

$\begin{array}{lllll}\text { (strongly disagree) } & \text { (disagree) } & \text { (neutral) } & \text { (agree) } & \text { (strongly agree) }\end{array}$

4. If you have a child/children with Type 1 diabetes, what was his/her/their most recent A1c? Please choose the number that is closest to this A1c value for each child:

\section{Child 1:}

$\begin{array}{llll}4 \% & 5 \% & 6 \% & 7 \%\end{array}$

$\begin{array}{llll}8 \% & 9 \% & 10 \% & 11 \%\end{array}$

$12 \% \quad 13 \% \quad 14 \% \quad 15 \%$
Child 2:

$\begin{array}{llll}4 \% & 5 \% & 6 \% & 7 \%\end{array}$

$\begin{array}{lllll}8 \% & 9 \% & 10 \% & 11 \%\end{array}$

$12 \% \quad 13 \% \quad 14 \% \quad 15 \%$
Child 3:

$4 \% \quad 5 \% \quad 6 \% \quad 7 \%$

$\begin{array}{llll}8 \% & 9 \% & 10 \% & 11 \%\end{array}$

$12 \% \quad 13 \% \quad 14 \% \quad 15 \%$
Child 4:

$\begin{array}{cccc}4 \% & 5 \% & 6 \% & 7 \% \\ 8 \% & 9 \% & 10 \% & 11 \% \\ 12 \% & 13 \% & 14 \% & 15 \%\end{array}$

\section{HISTORY OF CLINICAL TRIAL PARTICIPATION}

1. Are you aware that there are clinical trials for Type $\mathbf{1}$ diabetes?

$$
\begin{array}{ll}
\text { a } & \text { No } \\
\text { - } & \text { Yes }
\end{array}
$$

2. Are you aware that there are clinical trials for Type 1 diabetes at Vanderbilt?

$$
\begin{array}{ll}
\text { - No } \\
\text { Yes }
\end{array}
$$

3. From what sources have you received information about Type 1 diabetes clinical trials (including Vanderbilt sources and all other sources)?

None

Family/Friend

Healthcare provider (Nurse, Physician, etc.)

Media (internet, TV, radio, etc)

Other:

4. Was the information you received about Type 1 diabetes clinical trials easy to understand?
1
2
(not at all)
(a little)
3
(some)
5
(completely)
N/A
(a great deal)
(not applicable)

5. Have you ever been asked to enroll a child with Type 1 diabetes in a Type 1 diabetes clinical trial?

a No

- Yes, and I agreed to enroll every time I was asked.

- Yes, and I agreed to enroll some of the times I was asked.

- Yes, but I chose not to enroll every time I was asked.

6. Have you ever been asked to enroll a child who does not have Type 1 diabetes in a Type 1 diabetes clinical trial (ex: a clinical trial to prevent or better understand Type 1 diabetes)?

a Not applicable - I have no children that do not have Type 1 diabetes.

a No

- Yes, and I agreed to enroll every time I was asked.

- Yes, and I agreed to enroll some of the times I was asked.

- Yes, but I chose not to enroll every time I was asked. 
7. If you have been asked to enroll any of your children in a Type 1 diabetes clinical trial, do you feel that your healthcare providers gave you enough clear information to make the decision to enroll or not to enroll your child?

Not applicable - I have not been asked to enroll any children in a Type 1 diabetes clinical trial.

口 No

a Yes, some of the times.

- Yes, most of the times.

a Yes, all of the times.

8. If you were now approached about enrolling a child with Type 1 diabetes in a Type 1 diabetes clinical trial, how willing would you be to enroll him/her?

123
(not at all)
(a little)
(some)
(a great deal)
(completely)

9. If you were now approached about enrolling a non-diabetic child in a Type 1 diabetes clinical trial (ex: prevention trial), how willing would you be to enroll him/her?
1
2
(not at all)
(a little)
(some)
(a great deal)
5
N/A
(completely)
(Not Applicable)

CLINICAL TRIAL GOALS: A clinical trial is scientific research to generate knowledge for better medical practice. Please share with us how the goal of the clinical trial would affect your decision to enroll your child. How interested would you be in enrolling your child/children in studies with the following goals:
Not at all
1. Studies that may determine the risk of type 1 diabetes in my........ 1 non-diabetic children. child/children with diabetes.
3. Studies that may improve diabetes control for my child.............
2. Studies that may determine the risk of complications in my........ 1
4. Studies that may increase the time that my child with.............. 1 diabetes does not need shots (the "honeymoon" period).
5. Studies that may reverse ("cure") diabetes.......................
6. Studies that may prevent diabetes...
A great

$\begin{array}{llll}2 & 3 & 4 & 5 \\ 2 & 3 & 4 & 5\end{array}$

\section{INTEREST IN TYPES OF CLINICAL TRIALS}

1. Each clinical trial is different, so people who participate may have to do different things depending on the study. We would like to know more about how specific tasks that may be part of a Type 1 diabetes clinical trial may influence your decision to enroll your child. How comfortable would you feel if your child were asked to:
a. Give blood with a finger-prick
b. Have their blood drawn...
c. Take IV injections.

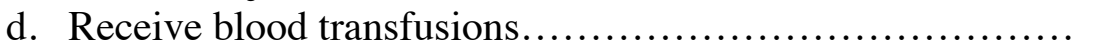
e. Do exercises
f. Be interviewed...
g. Stay in the hospital to receive medicine .......................
h. Have diet limited/restricted.................................
i. Take medicine by mouth.
Not at all

$\begin{array}{crrr}\text { A little } & \text { Some } & \begin{array}{c}\text { A great } \\ \text { deal }\end{array} & \text { Completely } \\ 2 & 3 & 4 & 5 \\ 2 & 3 & 4 & 5 \\ 2 & 3 & 4 & 5 \\ 2 & 3 & 4 & 5 \\ 2 & 3 & 4 & 5 \\ 2 & 3 & 4 & 5 \\ 2 & 3 & 4 & 5 \\ 2 & 3 & 4 & 5 \\ 2 & 3 & 4 & 5\end{array}$



j. Undergo surgery
Not at all
A little
k. Be exposed to animal tissues (ex: cow or pig islets).
Some
A great
1. Be exposed to human stem cells. ............................... 1
2
m. Receive a new vaccine
2
n. Receive a placebo (inactive medicine)
2

2. For the tasks where you marked "not at all" or only "a little" comfortable, please list any reasons why you were not as comfortable with these tasks:

3. There are lots of things that might affect a parent/guardian's decision to enroll a child in clinical trials. How much would the following influence your decision to enroll a child in a Type 1 diabetes clinical trial?

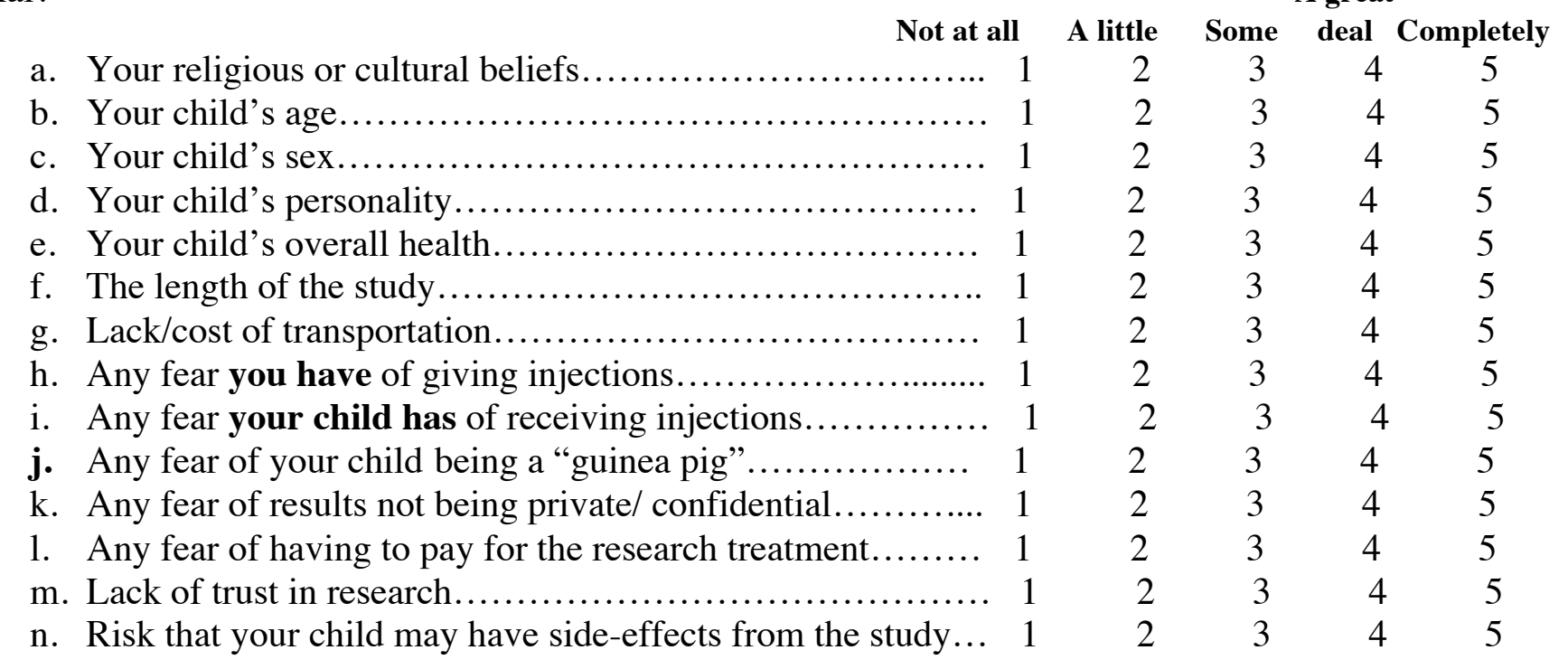

4. There are many things that might motivate or encourage a parent/guardian to enroll a child in clinical trials. How much would the following make you want to enroll a child in a Type 1 diabetes clinical trial?
a. Contributing to science
Not at all A little Some
b. Benefit for your child ....

$\begin{array}{ll}2 & 3 \\ 2 & 3 \\ 2 & 3 \\ 2 & 3\end{array}$
c. Benefit for other children in the future................. 1
d. More access to your doctor at no cost as................. 1 part of the study
e. Money/financial compensation

$\begin{array}{ll}2 & 3 \\ 2 & 3\end{array}$
deal Completely
f. Influence of friends and relatives.

A great 
TRIAL COMMITMENT: We would like to know more about how the degree of commitment involved in participating in Type 1 diabetes clinical trial may influence your decision to enroll your child. Please tell us what you think is appropriate to ask of you and your child in the following situations:

1. If your child were placed on an oral medicine, $\ldots \ldots \ldots \ldots . \quad 0 \quad 1 \quad \begin{array}{llllll}2 & 3 & 4 & 5 & \text { More }\end{array}$ how many times each day would you be willing times/day to administer it?

2. If your child were placed on an oral medicine, $\ldots \ldots \ldots \ldots .6 \quad 6$ mo $\quad \begin{array}{llllll}1 \mathrm{yr} & 2 \mathrm{yr} & 5 \mathrm{yr} & 10 \mathrm{yr} & \text { Lifetime }\end{array}$ for how long would you be willing to administer it?

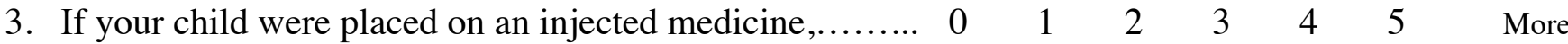
how many times each day would you be willing to administer it?

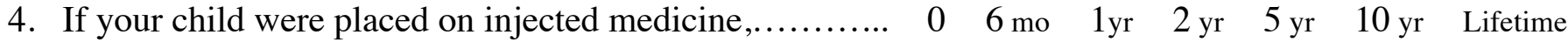
for how long would you be willing to administer it?

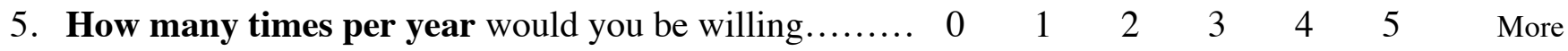
to allow your child's blood to be drawn?

6. How many times per year would you be willing........ to come to the clinic with your child? times/year More times/year

ATTITUDES TOWARDS CLINICAL TRIALS: Please read the following statements and indicate how much you agree with each by scoring on a scale from 1(strongly disagree) to 5 (strongly agree)
Strongly
disagree
1. My child's participation in Type 1 diabetes research is important to find a cure.
2. It is more important to give money to Type 1 diabetes........... 1 research than to participate in it.
3. Enough people are already participating in Type 1 diabetes........ 1 clinical trials.
4. Healthcare providers generally have the best interest of............. patients in mind when they ask them to enroll in clinical trials.
5. The decision to enroll my child in a clinical trial makes......
me uncomfortable because I feel it is a decision my child should make when he/she is old enough to do so.
6. I am afraid research may harm my child/children
7. Drug companies will prevent a cure from being tested..............
8. I would be uncomfortable with a trial that could cause any.......... increase in the risk of diabetes in my non-diabetic children.
9. I am afraid that a diabetes prevention trial could cause my......... 1 at-risk child to develop diabetes.
10. I would value protection from complications of diabetes.......... 1 almost as much as a cure.
11. If my child became uncomfortable (tummy ache, occasional....... 1 nausea with medicine) taking a medicine, I would withdraw from the trial.
12. I would give my non-diabetic child one shot every day........... 1 to delay diabetes for 5 years or more.

Thank you for completing our survey. Please slide it in the locked box when you are finished. 
ADDITIONAL COMMENTS: 